\title{
Improvement of Endovascular Stroke Treatment: A 24-Hour Neuroradiological On-Site Service Is Not Enough
}

\author{
Omid Nikoubashman $\mathbb{D}^{1},{ }^{1}$ Kolja Schürmann, ${ }^{2}$ Ahmed E. Othman, ${ }^{3}$ Jan-Philipp Bach, \\ Martin Wiesmann $\left(\mathbb{D},{ }^{1}\right.$ and Arno Reich ${ }^{2}$ \\ ${ }^{1}$ Department of Diagnostic and Interventional Neuroradiology, University Hospital, RWTH Aachen University, \\ Pauwelsstr. 30, 52074 Aachen, Germany \\ ${ }^{2}$ Department of Neurology, University Hospital, RWTH Aachen University, Pauwelsstr. 30, 52074 Aachen, Germany \\ ${ }^{3}$ Department of Radiology, University Hospital Tübingen, Hoppe-Seyler-Straße 3, 72076 Tübingen, Germany
}

Correspondence should be addressed to Omid Nikoubashman; onikoubashman@ukaachen.de

Received 31 July 2017; Revised 25 November 2017; Accepted 30 November 2017; Published 4 January 2018

Academic Editor: Marcel Arnold

Copyright (C) 2018 Omid Nikoubashman et al. This is an open access article distributed under the Creative Commons Attribution License, which permits unrestricted use, distribution, and reproduction in any medium, provided the original work is properly cited.

\begin{abstract}
Background and Purpose. With the advent of endovascular stroke treatment (EST) with mechanical thrombectomy, stroke treatment has also become more challenging. Purpose of this study was to investigate whether a fulltime neuroradiological on-site service and workflow optimization with a structured documentation of the interdisciplinary stroke workflow resulted in improved procedural times. Material and Methods. Procedural times of 322 consecutive patients, who received EST (1) before $(n=96)$ and (2) after $(n=$ 126) establishing a 24-hour neuroradiological on-site service as well as (3) after implementation of a structured interdisciplinary workflow documentation ("Stroke Check") $(n=100)$, were analysed. Results. A fulltime neuroradiological on-site service resulted in a nonsignificant improvement of procedural times during out-of-hours admissions $(p \geq 0.204)$. Working hours and out-of-hours procedural times improved significantly, if additional workflow optimization was realized $(p \leq 0.026)$. Conclusions. A 24-hour interventional on-site service is a major prerequisite to adequately provide modern reperfusion therapies in patients with acute ischemic stroke. However, simple measures like standardized and focused documentation that affect the entire interdisciplinary pre- and intrahospital stroke rescue chain seem to be important.
\end{abstract}

\section{Introduction}

As endovascular stroke treatment (EST) with mechanical thrombectomy has been established as a common treatment option for large vessel occlusion (LVO) acute ischemic stroke (AIS), stroke treatment has also become more challenging [1-6]. EST is based on a tightly coordinated interdisciplinary sequence of prehospital and in-house procedures that require an optimal workflow and manpower, especially at night or during weekends [7-9]. Almekhlafi et al. reported that inhouse procedures for EST take significantly longer time if patients are admitted out-of-hours [10, 11]. After a retrospective analysis of our procedural times in early 2012, we undertook various precautionary measures in order to improve procedure times and to avoid a possible out-ofhours effect. The most substantial countermeasures were (1) a fulltime neuroradiological on-site service and (2) consecutive workflow optimization with stringent interdisciplinary documentation, especially of key time intervals. We prospectively analysed the effects of these two countermeasures in order to investigate whether a fulltime neuroradiological on-site service and implementation of a structured interdisciplinary workflow documentation resulted in improved procedural times.

\section{Material and Methods}

2.1. Patients. Our analysis is based on a prospective observational registry of all consecutive patients of the University Hospital RWTH Aachen (Aachen, Germany) tertiary stroke centre, who received any kind of reperfusion therapy for AIS between February 2010 and March 2015. We chose 
this timeframe to allow for comparable sample sizes in our subgroups (see below). Between February 2010 and March 2015, 1009 patients with AIS received reperfusion therapy. We excluded 70 cases of in-house strokes from our study. This left 939 patients with a community-onset stroke. Of those 337 were transferred to the angiography suite for EST. After interdisciplinary neurological-neuroradiological treatment decision, 15 of the 337 patients did not receive EST and were excluded from our subgroup analysis. This left 322 patients, who received EST in our institution and who were included in our study.

In order to determine the effect of a fulltime neuroradiological on-site service and workflow optimization with extensive documentation of procedural times, we compared procedural times of three phases: (1) phase 0: all patients, who were admitted before establishing a $24 \mathrm{~h}$ neuroradiological on-site service in May 2012, (2) phase 1: all consecutive patients, who were admitted after establishing a $24 \mathrm{~h}$ neuroradiological onsite service but before workflow optimization with extensive documentation of procedural times in February 2014, (3) phase 2: all remaining consecutive patients after workflow optimization (Figure 1) with extensive documentation of procedural times ("Stroke Check," Figure 2).

2.2. Procedures and Workflow. The cornerstones of acute stroke treatment in our institution are (1) the neurological stroke team with vascular-experienced neurologists on-site 24 hours a day in the emergency department, (2) the supraregional comprehensive stroke unit (SU), (3) the neurological intensive care unit (NICU), and (4) the interventional neuroradiological team that is on-site during working-hours and on call (in a radius of 30 minutes) the rest of the time.

The rescue coordination centre informs the neurologist in charge about a stroke and the neurologist informs the neuroradiologist before the patient's arrival in the emergency room. Only if a short clinical examination confirms the stroke, the anaesthesiologist in charge is also informed and the patient is transferred to the CT suite, where an unenhanced CT is performed. Next, in the absence of medical contraindications, systemic thrombolysis is administered, followed by CT angiography and a CT perfusion. Alternatively, magnetic resonance imaging (MRI) is performed as first- or secondline imaging if CT imaging is (expected to be) nonconclusive. A patient is regarded as eligible for EST when there is clinical stroke, absence of haemorrhage or large infarction, and proven and accessible LVO. In addition, salvageable brain tissue (mismatch between cerebral blood volume and cerebral blood flow on CT perfusion imaging) is also considered whenever other criteria for EST are ambiguous (for example, in wake-up strokes). EST can be initiated after the time window of 4.5 hours if cranial imaging indicates that there is clinically relevant salvageable brain tissue. In every case, the interventional neuroradiologist and an experienced vascular neurologist (on call) discuss and decide about the therapy. Decision-making is based on medical and social criteria. Whenever possible the patient and/or the patient's relatives are involved in the decision-making process. If the decision to perform EST is made, the patient is transferred to the angiography suite. As all endovascular procedures

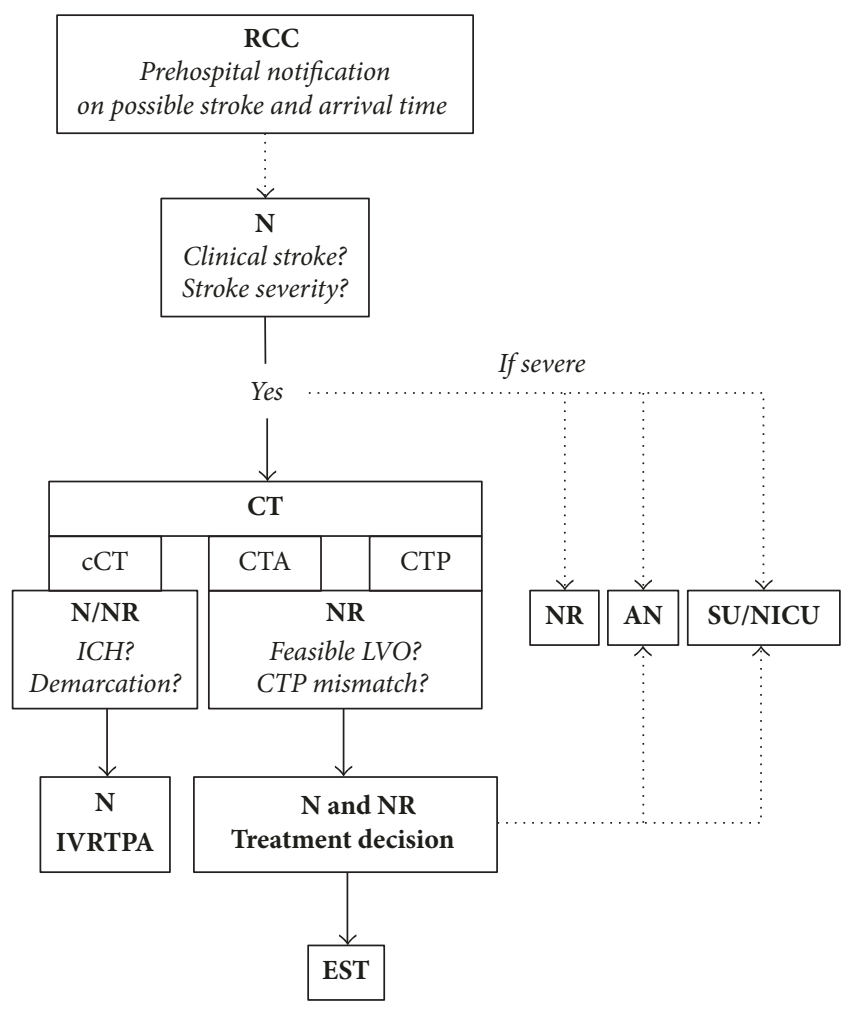

FIGURE 1: Schematic illustration of preinterventional workflow in our institution. RCC: rescue coordination centre; N: neurologist; NR: neuroradiologist; AN: anaesthesiologist; SU/NICU: stroke unit/neurological intensive care unit; CT: computed tomography; cCT: cranial CT; CTA: CT angiography; CTP: CT perfusion; ICH: intracranial/intracerebral haemorrhage; LVO: large vessel occlusion; IVRTPA: systemic thrombolysis; EST: endovascular stroke treatment. Dotted lines: phone calls. After the neurologist in charge is informed about a possible stroke by the rescue coordination centre, the neurologist informs the neuroradiologist in charge about the case. If a short clinical examination confirms the stroke, the anaesthesiologist on call is also informed and the patient is transferred to the CT suite, where the extent of stroke is assessed and an unenhanced CT is performed. In the meantime, the stroke unit or neurological intensive care unit is informed about the case. If there is no haemorrhage, and the patient fulfils standard inclusion criteria for thrombolysis, systemic thrombolysis is administered and a CT angiography is performed. If there is occlusion of a large cerebral artery, the interventionalist and the anaesthesiologist are informed and the patient is transferred to the angiography suite. In the angiography suite, there is parallel workflow with the interventionalist performing the groin puncture, while the anaesthesiologist intubates the patient.

are performed using general anaesthesia, there is parallel workflow with the interventionalist performing the groin puncture, while the anaesthesiologist intubates the patient. Standard endovascular treatment with and without stent retrievers is performed as reported previously [12].

2.3. Clinical, Procedural, and Radiological Data. After obtaining permission from our local ethics board, we assessed demographical data, clinical presentation (NIHSS) and disability (mRS) on admission, and disability at follow-up (mRS 
Emergency services: Municipaly of Aachen - District Düren - District Heinsberg • Aachen Suburban Region

\section{Neurovascular web Region of Aachen (NVNAC)}

Cooperating hospitals: www.nvnac.ukaachen.de
Coordinating hospital:

Uniklinik RWTH Aachen

Cooperating stroke units:

Düren (St. Augustinus Krankenhaus)

Erkelenz (Hermann-Josef-Krankenhaus) Würselen (Medizinisches Zentrum)

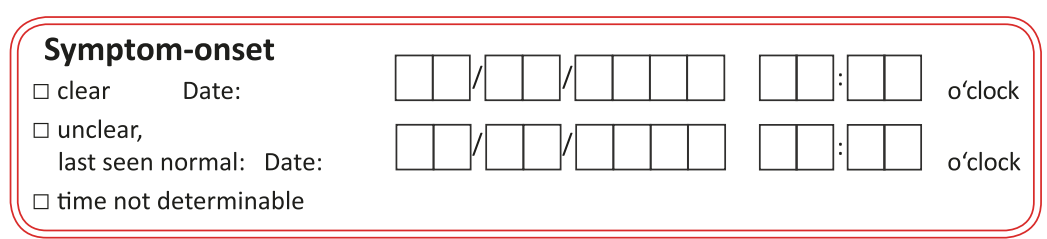

\begin{tabular}{|ll|l|l|}
$\square$ In-hospital stroke & & \\
\cline { 2 - 2 } & & & \\
$\square$ Time of referral & (department) & & o'clock \\
\hline
\end{tabular}

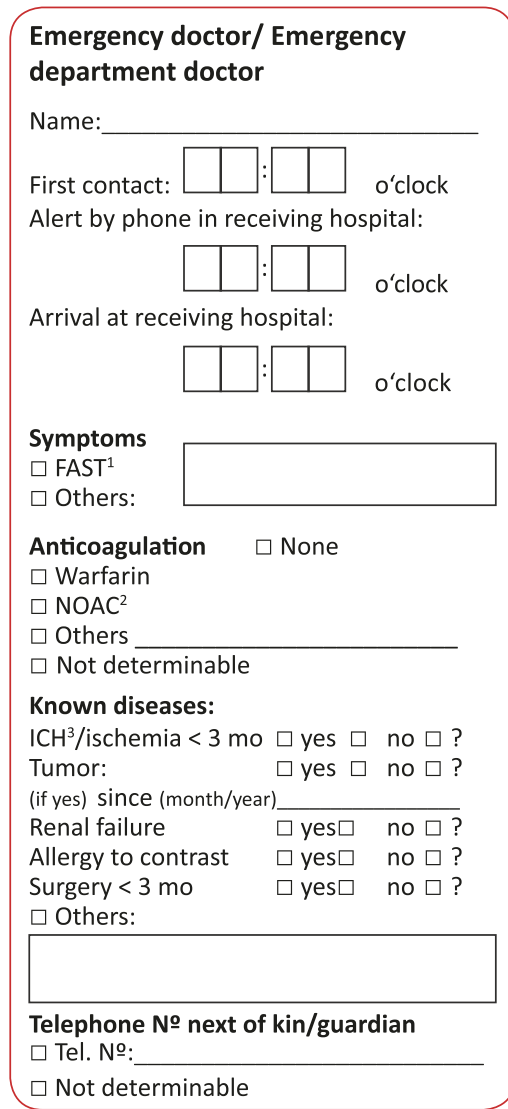

\section{Handover}

$\square$ Delivery of

emergency doctor's protocol

Hemodynamically

$\square$ Stable $\square$ Unstable

ECG present

$\square$ yes $\square$ no

Peripheral vein catheter exists

$\square$ yes $\quad \square$ no

Serum glucose \begin{tabular}{l|l|l|l}
\cline { 2 - 3 } & & & \\
$\mathrm{mg} / \mathrm{dl}$
\end{tabular}

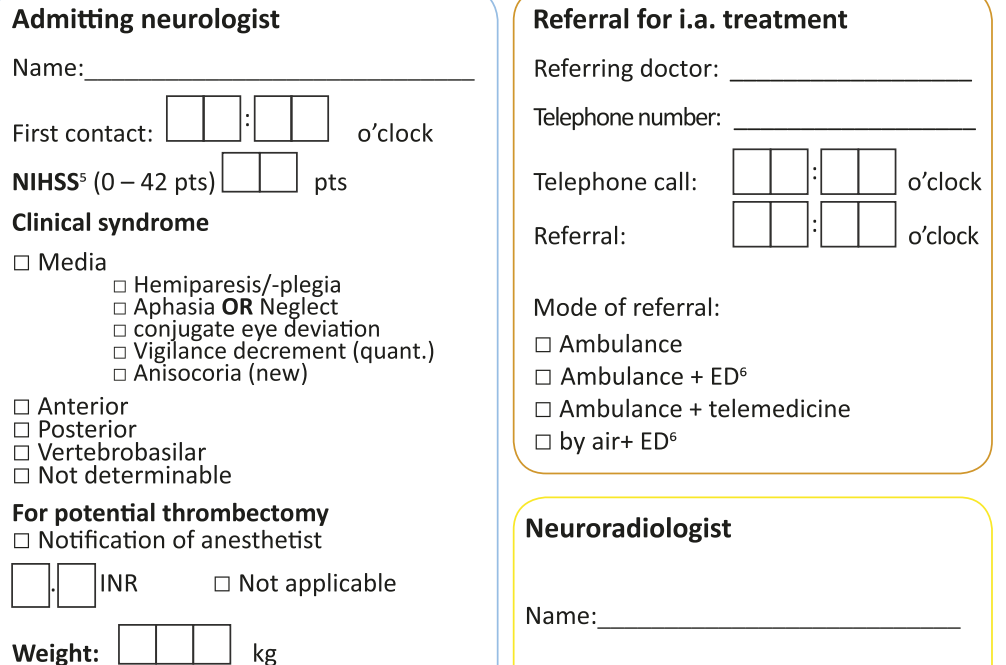

Weight: \begin{tabular}{l|l|l|l}
\hline & & & $\mathrm{kg}$
\end{tabular}

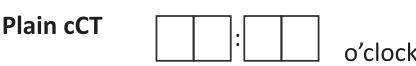

$\square$ Exclusion $\mathrm{ICH}^{3}$

Criteria for i.v. thrombolysis met?

$\square$ yes $\square$ no

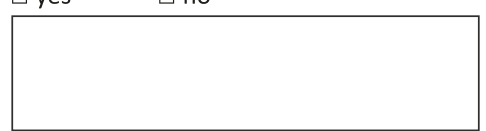

Emergency or stroke unit doctor I.v. thrombolysis

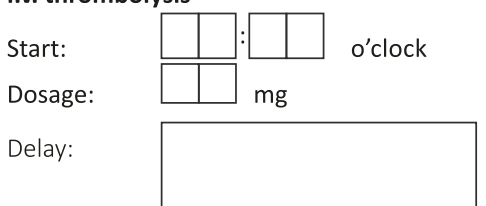

\section{Stroke unit doctor}

Name:

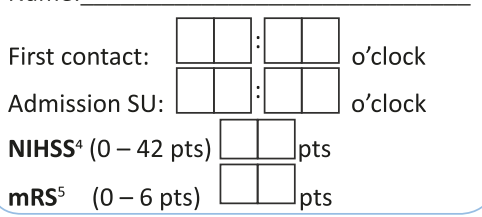

Anesthetist

\section{STROKE CHECK}

Patient registration

Aachen (UKA) +49 241 80-80173

Düren (SAK) +49 $2421599-6753$

Erkelenz (HJK) +49 2431894700

Würselen (MZ) +49 2405 62-7480

Patient sticker

Patient:

Age (years):

\begin{tabular}{|c|c|}
\hline \multicolumn{2}{|c|}{ Referral for i.a. treatment } \\
\hline Referring doctor: & \\
\hline \multicolumn{2}{|l|}{ Telephone number: } \\
\hline Telephone call: & o'clock \\
\hline Referral: & o'clock \\
\hline \multicolumn{2}{|l|}{ Mode of referral: } \\
\hline \\
\hline \multicolumn{2}{|c|}{$\square$ Ambulance $+E D^{6}$} \\
\hline \multicolumn{2}{|c|}{$\square$ Ambulance + telemedicine } \\
\hline \multicolumn{2}{|c|}{$\square$ by air+ED } \\
\hline \multicolumn{2}{|l|}{ Neuroradiologist } \\
\hline Name: & \\
\hline
\end{tabular}

Therapy decision $(\mathrm{N} / \mathrm{NR})^{7}$

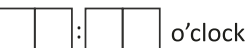

Arrival:

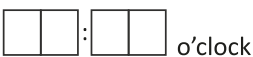

Management

$\square$ Concious

sedation:

$\square$ Intubation:

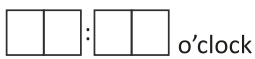

Intervention

Arterial puncture: $\square: \square: \square$ o'clock

Recanalization:

First:

Final:

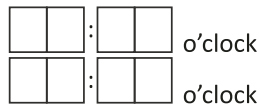

TICl Score ${ }^{8} \square$

Remarks:

IFace-Arm-Speech-Test; 2 new oral anticoagulant; 3 intracranial hemorrage; 4 National Institute of Health Stroke Scale; 5 modified Rankin-Scale; 6 Emergency doctor; 7 neurologist and neuroradiologist on call; 8 Thrombolysis in Cerebral infartion Score $(0,1,2 a, 2 b, 3)$

FIGURE 2: "Stroke Check" form for interdisciplinary documentation of treatment related data. Initial NIHSS scores and follow-up mRS are documented on the back of the sheet. 
at discharge and day 90), cerebrovascular risk factors and primary as well as prophylactic use of antiplatelet/anticoagulant medication, and ischemic stroke aetiology (adapted from TOAST) [13]. Two neuroradiologists, who were blinded to clinical data, evaluated radiological data. A reference standard was established for statistical analyses in a consensus reading. Radiological and procedural data comprised initial and postinterventional/follow-up imaging with site of LVO and extent of initial ischemic changes (ASPECTS), type of treatment (including systemic therapy), procedural time intervals, and result of recanalization (TICI) [14, 15]. Door-toimage time was defined as the time between the documented time of admission in the emergency department and completion of the first cerebral imaging with computed tomography or magnetic resonance imaging. Image-to-puncture time was defined as the time between completion of the first cerebral imaging with CT or MRI to groin puncture in the angiography suite. Puncture-to-revascularization time was defined as the time between groin puncture in the angiography suite and first revascularization of the affected vessel (relative TICI improvement $\geq 1$ ). Primary outcome measures were procedural times as defined above and functional outcome defined as $m R S$ of $\leq 2$ after 90 days.

2.4. Statistical Analysis. Pearson's $\chi^{2}$ tests and Fisher's exact tests were used whenever applicable. Student's $t$ tests, Mann-Whitney $U$ tests, and analysis of variance (ANOVA) were used for comparison of continuous data after testing for normal distribution with a Shapiro-Wilk test. $p$ values under the alpha level of 0.05 were defined as significant. All statistical analyses were performed with SPSS 23 software (IBM, Armonk, New York).

\section{Results}

Ninety-six patients received interventional treatment before establishing a 24-7 neuroradiological service (phase 0). Fiftythree $(55 \%)$ of these patients were admitted out-of-hours. Procedural times of patients admitted in working-hours and out-of-hours did not differ significantly. Median intervals for working-hours versus out-of-hours admissions were as follows: door-to-image: 26 versus 26 minutes $(p=0.405)$, image-to-puncture: 58 versus 61 minutes $(p=0.448)$, puncture-to-revascularization: 65 versus 61 minutes $(p=$ 0.811 ), and door-to-revascularization: 161 versus 171 minutes $(p=0.380)$ (Figure 3$)$. Working-hours versus out-ofhours admissions did not differ significantly with regard to favourable functional outcome rate (15/37 versus $16 / 42 ; p=$ $0.824)$ at 90 days.

One hundred twenty-six patients received interventional treatment after introduction of a fulltime neuroradiological on-site service but before workflow optimization with extensive documentation of procedural times (phase 1). Seventy (56\%) of these patients were admitted out-of-hours. Procedural times of patients admitted in working-hours and out-of-hours did not differ significantly. Median intervals for working-hours versus out-of-hours admissions were as follows: door-to-image: 26.5 versus 28 minutes $(p=0.418)$, image-to-puncture: 52.5 versus 56 minutes $(p=0.124)$, puncture-to-revascularization: 66 versus 69 minutes $(p=$ $0.506)$, and door-to-revascularization: 151 versus 163 minutes $(p=0.214)$ (Figure 3$)$. Working-hours versus out-ofhours admissions did not differ significantly with regard to favourable functional outcome rate (14/51 versus $20 / 63 ; p=$ 0.618 ) at 90 days.

One hundred patients received interventional treatment after workflow optimization with extensive documentation of procedural times (phase 2). Sixty-three (63\%) of these patients were admitted out-of-hours. Procedural times of patients admitted in working-hours and out-of-hours did not differ significantly. Median intervals for working-hours versus out-of-hours admissions were as follows: door-toimage: 23 versus 21 minutes $(p=0.526)$, image-topuncture: 43.5 versus 48 minutes $(p=0.109)$, punctureto-revascularization: 45 versus 59 minutes $(p=0.214)$, and door-to-revascularization: 112.5 versus 139.5 minutes $(p=0.158)$ (Figure 3$)$. Working-hours versus out-ofhours admissions did not differ significantly with regard to favourable functional outcome rate $(2 / 24$ versus $15 / 52 ; p=$ 0.074 , Fisher's exact test) at 90 days.

3.1. Development of Procedural Times and Clinical Outcome. Procedural times improved slightly after establishing a 24hour neuroradiological on-site service in May 2012 (Table 1 and Figure 3). However, both during working-hours admissions and out-of-hours admissions, changes in door-to-image ( $p=0.535$ and $p=0.604)$, image-to-puncture $(p=0.209$ and $p=0.268)$, puncture-to-revascularization $(p=0.538$ and $p=0.984)$, and door-to-revascularization times $(p=$ 0.205 and $p=0.204$ ) failed to reach statistical significance.

In out-of-hours admissions, additional workflow optimization with extensive documentation of procedural times had a significant impact on door-to-image $(p<0.001)$, image-to-puncture $(p=0.013)$, and door-to-revascularization times $(p=0.024)$. Changes in punctureto-revascularization time failed to reach statistical significance ( $p=0.259)$. In working-hours admissions, the same measures resulted in significantly shorter door-torevascularization times $(p=0.026)$. However, when changes in door-to-image $(p=0.061)$, image-to-puncture $(p=$ $0.063)$, and puncture-to-revascularization times $(p=0.096)$ were regarded separately, these changes failed to reach statistical significance.

In out-of-hours admissions, establishing a fulltime neuroradiological on-site service combined with workflow optimization with extensive documentation of procedural times resulted in significantly improved door-to-image $(p<$ $0.001)$, image-to-puncture $(p=0.003)$, and door-torevascularization times $(p=0.001)$, whereas punctureto-revascularization times $(p=0.365)$ did not change significantly. In working-hours admissions all procedural times, including door-to-image $(p=0.029)$, image-topuncture $(p=0.006)$, puncture-to-revascularization $(p=$ $0.045)$, and door-to-revascularization times $(p=0.006)$, improved significantly during the same period. 

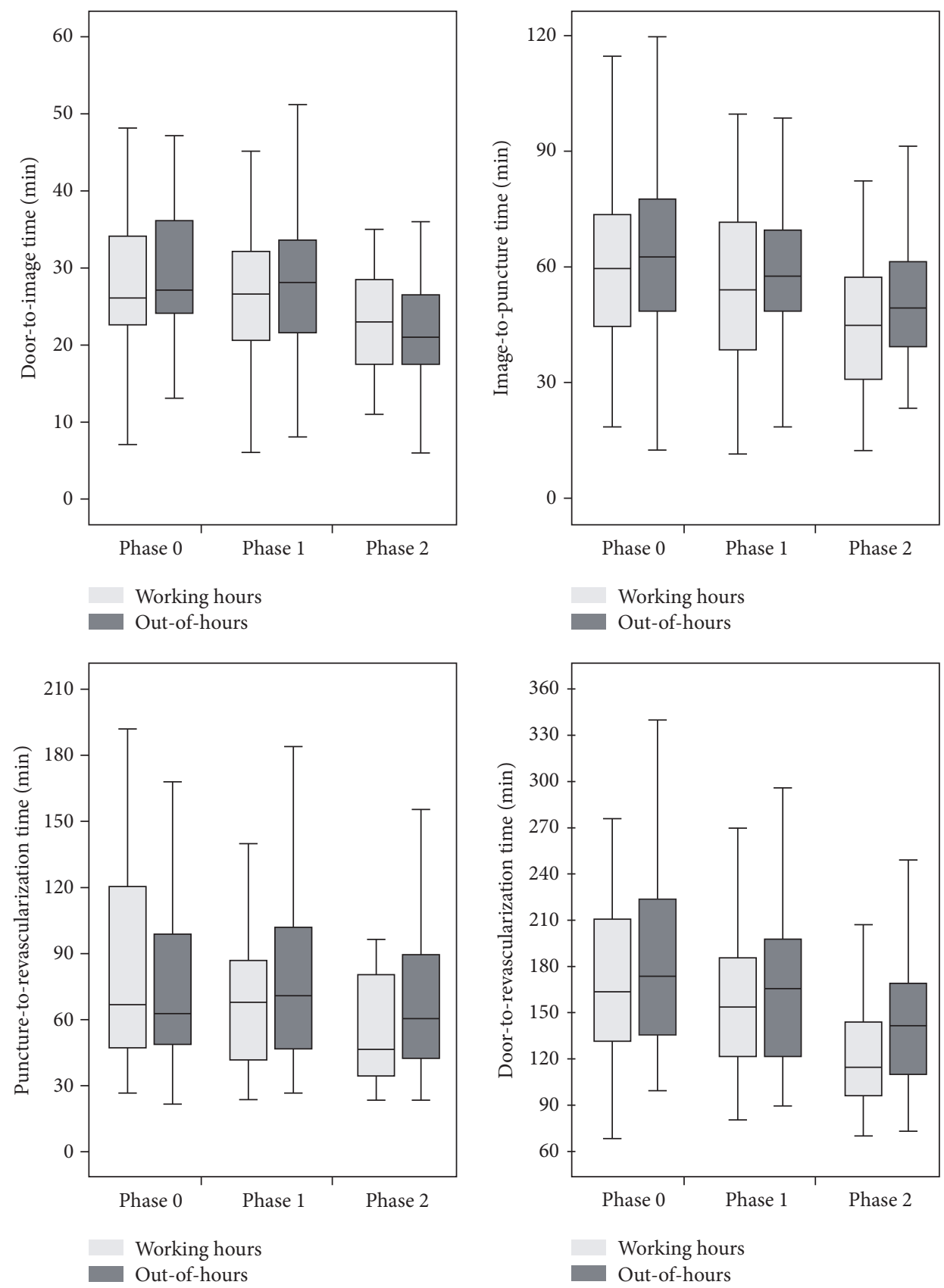

FIGURE 3: Boxplots illustrating procedural times. Outliers are not illustrated. Phase 0: before establishing a 24 h neuroradiological on-site service in May 2012. Phase 1: after introduction of a $24 \mathrm{~h}$ neuroradiological on-site service but before workflow optimization with extensive documentation of procedural times in February 2014. Phase 3: after workflow optimization with extensive documentation of procedural times.

\section{Discussion}

With the introduction of a fulltime neuroradiological onsite service, we aimed to accelerate our procedural times and achieved slight improvements. We expected that the out-of-hours presence of a neuroradiologist would result in acceleration of image-to-puncture times and to a lesser degree also door-to-image times. However, a fulltime neuroradiological on-site service resulted only in a nonsignificant improvement of procedural times. A significant acceleration of procedural times could only be achieved when also the interdisciplinary workflow was optimized: in February 2014 we implemented a modified stroke workflow involving all participating parties beginning from the surrounding rescue coordination centres to our stroke unit and intensive care units [16-18]. We modified our chain of information with early notification of the neuroradiologist and the anaesthesiologist in charge of all possible endovascular cases by the neurologist (Figure 1). In order to raise awareness of procedural times, we introduced uniform documentation 
TABLE 1: Overview of included patients. Phase 0: before establishing a $24 \mathrm{~h}$ neuroradiological on-site service in May 2012. Phase 1: after introduction of a $24 \mathrm{~h}$ neuroradiological on-site service but before workflow optimization with extensive documentation of procedural times in February 2014. Phase 2: after workflow optimization with extensive documentation of procedural times. NIHSS: national institute for health stroke scale; mRS: modified Rankin scale; ASPECTS Alberta stroke program early CT score. ICA: internal carotid artery; MCA: middle cerebral artery; ACA: anterior cerebral artery; VA: vertebral artery; BA: basilar artery; PCA: posterior cerebral artery. IA: intra-arterial. EST: endovascular stroke treatment. Values expressed as means \pm standard deviation if not indicated otherwise.

\begin{tabular}{|c|c|c|c|c|}
\hline & Phase 0 & Phase 1 & Phase 2 & $p$ value \\
\hline \multicolumn{5}{|l|}{ Demographics } \\
\hline Age $(\mathrm{yr})(n)$ & $\begin{array}{c}69.8 \pm 15.7 \text { (median, 72.9 } \\
\text { IQR, 16.5) }\end{array}$ & $\begin{array}{c}71.5 \pm 12.7 \text { (median, } 72.1 \\
\text { IQR, 18.1) }\end{array}$ & $\begin{array}{l}70.4 \pm 14.2(\text { median } \\
72.9 ; \mathrm{IQR}, 16.7)\end{array}$ & 0.673 \\
\hline Male sex $(n)$ & $52(54.2 \%)$ & $63(50.0 \%)$ & $43(43.0 \%)$ & 0.284 \\
\hline \multicolumn{5}{|l|}{ Medical history } \\
\hline Hypertension $(n)$ & $69(71.9 \%)$ & $100(79.4 \%)$ & $83(82.0 \%)$ & 0.156 \\
\hline Diabetes $(n)$ & $26(27.1 \%)$ & $22(17.5 \%)$ & $35(35.0 \%)$ & $0.011^{*}$ \\
\hline Fat metabolism disorder $(n)$ & $36(37.5 \%)$ & $38(30.2 \%)$ & $23(23.0 \%)$ & 0.087 \\
\hline Adiposity $(n)$ & $31(32.3 \%)$ & $30(23.8 \%)$ & $21(21.0 \%)$ & 0.166 \\
\hline Nicotine $(n)$ & $22(22.9 \%)$ & $35(27.8 \%)$ & $20(20.0 \%)$ & 0.381 \\
\hline Cardiovascular disease $(n)$ & $49(51.0 \%)$ & $69(54.8 \%)$ & $29(29.0 \%)$ & $<0.001^{*}$ \\
\hline Atrial fibrillation $(n)$ & $47(49.0 \%)$ & $61(48.4 \%)$ & $51(51.0 \%)$ & 0.924 \\
\hline Prior stroke $(n)$ & $16(16.7 \%)$ & $23(18.3 \%)$ & $19(19.0 \%)$ & 0.910 \\
\hline Current antiplatelet use $(n)$ & $26 / 93(28.0 \%)$ & $34 / 121(28.1 \%)$ & $27 / 82(32.9 \%)$ & 0.711 \\
\hline Current anticoagulant use $(n)$ & $8(8.3 \%)$ & $16(12.7 \%)$ & $16(16.0 \%)$ & 0.264 \\
\hline \multicolumn{5}{|l|}{ Clinical baseline } \\
\hline NIHSS on admission & $\begin{array}{c}17.6 \pm 7.0(\text { median, } 17.0 \\
\text { IQR, } 8)\end{array}$ & $\begin{array}{c}17.9 \pm 7.2(\text { median, } 18.0 \\
\text { IQR, } 6)\end{array}$ & $\begin{array}{c}17.6 \pm 5.5 \text { (median, 19.0; } \\
\text { IQR, 3) }\end{array}$ & 0.935 \\
\hline mRS on admission & $\begin{array}{c}4.6 \pm 0.6 \text { (median, } 5.0 \\
\text { IQR, } 1 \text { ) }\end{array}$ & $\begin{array}{c}4.5 \pm 0.7 \text { (median, } 5.0 ; \\
\text { IQR, 1) }\end{array}$ & $\begin{array}{c}4.5 \pm 0.6 \text { (median, } 5.0 ; \\
\text { IQR, 1) }\end{array}$ & 0.734 \\
\hline \multicolumn{5}{|l|}{ Site of vessel occlusion } \\
\hline Anterior circulation (ICA, MCA, ACA) $(n)$ & $81(84.4 \%)$ & $108(85.7 \%)$ & $86(86.0 \%)$ & \multirow{2}{*}{0.942} \\
\hline Posterior circulation (VA, BA, PCA) $(n)$ & $15(15.6 \%)$ & $18(14.3 \%)$ & $14(14.0 \%)$ & \\
\hline Initial ASPECT score & $\begin{array}{c}9.0 \pm 1.4(\text { median, } 10.0 \\
\text { IQR }, 2)\end{array}$ & $\begin{array}{c}8.9 \pm 1.6(\text { median, } 9.5 \\
\text { IQR }, 1)\end{array}$ & $\begin{array}{c}7.6 \pm 3.4 \text { (median, 9.0 } \\
\text { IQR, 4) }\end{array}$ & $<0.001^{*}$ \\
\hline \multicolumn{5}{|l|}{ Time intervals } \\
\hline Onset to door ( $\mathrm{min})$ & $\begin{array}{c}89.7 \pm 92.5(\text { median, 61.0 } \\
\text { IQR, 50) }\end{array}$ & $\begin{array}{c}111.3 \pm 76.8(\text { median } \\
\text { 95.0; IQR, 92) }\end{array}$ & $\begin{array}{c}96.9 \pm 63.8(\text { median } \\
79.5 ; \mathrm{IQR}, 73)\end{array}$ & 0.247 \\
\hline Door to image (min) & $\begin{array}{c}30.6 \pm 15.9 \text { (median, 27.0 } \\
\text { IQR, 12) }\end{array}$ & $\begin{array}{c}27.81 \pm 9.9(\text { median, } 28.0 \\
\text { IQR }, 12)\end{array}$ & $\begin{array}{l}24.0 \pm 11.2(\text { median } \\
22.0 ; \mathrm{IQR}, 10)\end{array}$ & $0.001^{*}$ \\
\hline Image to puncture (min) & $\begin{array}{c}66.4 \pm 34.0(\text { median, } 60.0 \\
\text { IQR, 33) }\end{array}$ & $\begin{array}{c}56.8 \pm 22.3(\text { median, 53.0 } \\
\text { IQR, 55) }\end{array}$ & $\begin{array}{c}47.6 \pm 18.6(\text { median } \\
46.0 ; \mathrm{IQR}, 23)\end{array}$ & $<0.001^{*}$ \\
\hline Puncture to revascularization (min) & $\begin{array}{c}87.0 \pm 58.9(\text { median, } 64.5 \\
\text { IQR }, 68)\end{array}$ & $\begin{array}{c}77.9 \pm 46.2(\text { median, } 67.5 \\
\text { IQR }, 62)\end{array}$ & $\begin{array}{c}71.5 \pm 49.9(\text { median } \\
54.5 ; \mathrm{IQR}, 55)\end{array}$ & 0.100 \\
\hline Door to revascularization (min) & $\begin{array}{c}188.5 \pm 84.4(\text { median } \\
\text { 171.0; IQR, 86) }\end{array}$ & $\begin{array}{c}162.4 \pm 52.6(\text { median } \\
156.0 ; \mathrm{IQR}, 72)\end{array}$ & $\begin{array}{c}150.4 \pm 71.8(\text { median } \\
129.0 ; \text { IQR }, 66)\end{array}$ & $0.001^{*}$ \\
\hline Onset to revascularization ( $\mathrm{min}$ ) & $\begin{array}{c}268.0 \pm 116.2(\text { median } \\
233.5 ; \mathrm{IQR}, 121)\end{array}$ & $\begin{array}{c}265.8 \pm 97.8(\text { median } \\
254.5 ; \mathrm{IQR}, 106)\end{array}$ & $\begin{array}{l}239.6 \pm 91.1(\text { median } \\
216.0 ; \mathrm{IQR}, 118)\end{array}$ & 0.244 \\
\hline \multicolumn{5}{|l|}{ Interventional procedures } \\
\hline Systemic thrombolysis $(n)$ & $69(71.9 \%)$ & $87(69.0 \%)$ & $67(67.0 \%)$ & 0.759 \\
\hline IA thrombolysis $(n)$ & $34(35.4 \%)$ & $28(22.2 \%)$ & $9(9.0 \%)$ & $<0.001^{*}$ \\
\hline Stent retriever $(n)$ & $77(80.2 \%)$ & $118(93.7 \%)$ & $97(97.0 \%)$ & $<0.001^{*}$ \\
\hline \multicolumn{5}{|l|}{ Outcome } \\
\hline Successful revascularization $(\mathrm{TICI} \geq 2 \mathrm{~b})(n)$ & $80(83.3 \%)$ & $104(82.5 \%)$ & $86(86.0 \%)$ & 0.771 \\
\hline Good clinical outcome $(\mathrm{mRS} \leq 2 \mathrm{~d} 90)(n)$ & $31 / 79(39.2 \%)$ & $34 / 114(29.8 \%)$ & $18 / 78(23.1 \%)$ & 0.087 \\
\hline Death $(\mathrm{d} 90)(n)$ & $24 / 79(30.4 \%)$ & $38 / 114(33.3 \%)$ & $29 / 78(37.2 \%)$ & 0.664 \\
\hline
\end{tabular}

${ }^{*} p$ values $<0.05$ were considered significant. 
throughout the complete rescue chain, including extensive documentation of procedural times by both the neurologists and the neuroradiologists (Figure 2). These measures resulted in a highly significant reduction of door-to-image, imageto-puncture, and door-to-revascularization times in out-ofhours admissions. By combining a fulltime neuroradiological on-site service and comparatively simple and inexpensive workflow optimization, we were able to significantly reduce almost all procedural times in both working-hours and outof-hours admissions without creating a weekend-effect. In particular, we were able to accelerate in-hospital procedures that rely on efficient teamwork (reflected in door-to-image and image-to-puncture times). In working-hours we were also able to accelerate puncture-to-revascularization times, a measure that rather reflects the speed of the actual thrombectomy than organizational workflow. However, we were not able to reduce puncture-to-revascularization times in outof-hours admissions. This finding is surprising as punctureto-revascularization times reflect the type of LVO and the interventionalists' experience rather than workflow issues. It is conceivable but unlikely that interventionalists simply take their time in out-of-hours admissions. However, our findings may rather imply that there are organizational issues (i.e., preparation of the procedure and assistance during the procedure) that cannot be overcome with a reduced staff of radiographers and assistants. Identifying specific factors that could improve procedural times should be subject of further studies.

In times of highly effective EST in AIS patients with LVO, it is mandatory to optimize all steps within the stroke rescue chain. Extensive intrahospital workflow optimization with specific standard operating procedures for all disciplines, that is, emergency physicians, neurologists, (neuro)radiologists, and anaesthesiologists, as well as for physicians, nurses, technical assistants, transportation, and registration staff, combined with constant feedback mechanisms, can dramatically improve procedural times and therewith outcome of patients [19]. Likewise, logistic and technical changes, as, for example, one-stop management using the latest generation of flat detector $\mathrm{CT}$, have the potential to improve intrahospital treatment intervals. However, most of these measures are not easy to implement and do not affect the prehospital interval [20]. In this work, we introduced an inexpensive and easy to implement stroke documentation tool that covers the entire stroke rescue chain. It helps to improve treatment intervals and can serve as a quality control tool.

Surprisingly, our measures had no impact on clinical outcome at follow-up. This is unexpected as clinical outcome is time-dependent [21]. The fact that our improved procedural times are not reflected in improved clinical outcome is likely owed by the fact that our inclusion criteria became more ambitious over time, resulting in inclusion of patients with significantly larger infarctions (Table 1), hence less favourable expected benefit.

Limitations. We aimed to investigate the impact of a fulltime neuroradiological on-site service on procedural times in outof-hours admissions. A major limitation of our study is that our results cannot easily be transferred to any other hospital, given the specific infrastructural and organizational structures in every hospital. A major limitation is also owed to the nature of our study as procedural times are influenced by multiple factors and as a neuroradiological on-site service is no isolated variable that can be analysed independently. We anticipated this issue by including a large number of patients and accounting for various possible covariates.

\section{Conclusions}

Our results imply that a fulltime neuroradiological on-site service accelerates procedural times, but that changes are only significant if there is also workflow optimization of the entire interdisciplinary pre- and intrahospital stroke rescue chain. By combining a fulltime neuroradiological on-site service and workflow optimization via uniform documentation throughout the rescue chain, we were able to significantly reduce almost all procedural times of both working-hours and out-of-hours admissions without creating a weekend effect.

\section{Conflicts of Interest}

The authors declare that they have no conflicts of interest.

\section{References}

[1] J. L. Saver, M. Goyal, A. Bonafe et al., "Stent-retriever thrombectomy after intravenous t-PA vs. t-PA alone in stroke," The New England Journal of Medicine, vol. 372, no. 24, pp. 2285-2295, 2015.

[2] O. A. Berkhemer, P. S. Fransen, D. Beumer et al., "A randomized trial of intraarterial treatment for acute ischemic stroke," The New England Journal of Medicine, vol. 372, no. 1, pp. 11-20, 2015.

[3] B. C. Campbell, P. J. Mitchell, T. J. Kleinig et al., "Endovascular therapy for ischemic stroke with perfusion-imaging selection," The New England Journal of Medicine, vol. 372, no. 11, pp. 10091018, 2015.

[4] T. G. Jovin, A. Chamorro, E. Cobo et al., "Thrombectomy within 8 hours after symptom onset in ischemic stroke," The New England Journal of Medicine, vol. 372, no. 24, pp. 2296-2306, 2015.

[5] M. Goyal, A. M. Demchuk, B. K. Menon et al., "Randomized assessment of rapid endovascular treatment of ischemic stroke," The New England Journal of Medicine, vol. 372, no. 11, pp. 10191030, 2015.

[6] O. Nikoubashman, M. Jungbluth, K. Schürmann et al., "Neurothrombectomy in acute ischaemic stroke: A prospective single-centre study and comparison with randomized controlled trials," European Journal of Neurology, vol. 23, no. 4, pp. 807-816, 2016.

[7] M. Goyal, B. K. Menon, M. D. Hill, and A. Demchuk, "Consistently achieving computed tomography to endovascular recanalization < 90 minutes: solutions and innovations," Stroke; a Journal of Cerebral Circulation, vol. 45, no. 12, pp. e252-e256, 2014.

[8] S. M. Van Schaik, S. Scott, L. M. de Lau, R. M. Van den BergVos, and N. D. Kruyt, "Short Door-to-Needle Times in Acute Ischemic Stroke and Prospective Identification of Its Delaying Factors," Cerebrovascular Diseases Extra, vol. 5, no. 2, pp. 75-83, 2015. 
[9] O. Nikoubashman, T. Probst, K. Schürmann et al., "Weekend effect in endovascular stroke treatment: Do treatment decisions, procedural times, and outcome depend on time of admission?" Journal of NeuroInterventional Surgery, vol. 9, no. 4, pp. 336-339, 2017.

[10] M. A. Almekhlafi, A. Hockley, J. A. Desai et al., "Overcoming the evening/weekend effects on time delays and outcomes of endovascular stroke therapy: The Calgary Stroke Program experience," Journal of NeuroInterventional Surgery, vol. 6, no. 10, pp. 729-732, 2014.

[11] A. Mpotsaris, A. Kowoll, W. Weber, C. Kabbasch, A. Weber, and D. Behme, "Endovascular stroke therapy at nighttime and on weekends-as fast and effective as during normal business hours?" Journal of Vascular and Interventional Neurology, vol. 8, no. 1, pp. 39-45, 2015.

[12] O. Nikoubashman, A. Reich, R. Pjontek, M. Jungbluth, and M. Wiesmann, "Postinterventional subarachnoid haemorrhage after endovascular stroke treatment with stent retrievers," Neuroradiology, vol. 56, no. 12, pp. 1087-1096, 2014.

[13] H. P. Adams Jr., B. H. Bendixen, L. J. Kappelle et al., "Classification of subtype of acute ischemic stroke: definitions for use in a multicenter clinical trial," Stroke, vol. 24, no. 1, pp. 35-41, 1993.

[14] J. E. Fugate, A. M. Klunder, and D. F. Kallmes, "What is meant by “TICI”?" American Journal of Neuroradiology, vol. 34, no. 9, pp. 1792-1797, 2013.

[15] J. H. W. Pexman, P. A. Barber, M. D. Hill et al., "Use of the Alberta Stroke Program Early CT Score (ASPECTS) for assessing CT scans in patients with acute stroke," American Journal of Neuroradiology, vol. 22, no. 8, pp. 1534-1542, 2001.

[16] A. Meretoja, D. Strbian, S. Mustanoja, T. Tatlisumak, P. J. Lindsberg, and M. Kaste, "Reducing in-hospital delay to 20 minutes in stroke thrombolysis," Neurology, vol. 79, no. 4, pp. 306-313, 2012.

[17] H.-J. Cho, K. Y. Lee, H. S. Nam et al., "Process improvement to enhance existing stroke team activity toward more timely thrombolytic treatment," Journal of Clinical Neurology, vol. 10, no. 4, pp. 328-333, 2014.

[18] E. T. Thortveit, M. G. Bøe, U. Ljøstad, Å. Mygland, and A. Tveiten, "Organizational changes aiming to reduce iv tPA doorto-needle time," Acta Neurologica Scandinavica, vol. 130, no. 4, pp. 248-252, 2014.

[19] K. Schregel, D. Behme, I. Tsogkas et al., "Effects of Workflow optimization in endovascularly treated stroke patients - a prepost effectiveness study," PLOS ONE, vol. 11, no. 12, article e0169192, 2016.

[20] M. Psychogios, D. Behme, K. Schregel et al., "One-stop management of acute stroke patients," Stroke, vol. 48, no. 11, pp. 31523155, 2017.

[21] P. Khatri, T. Abruzzo, S. D. Yeatts, C. Nichols, J. P. Broderick, and T. A. Tomsick, "Good clinical outcome after ischemic stroke with successful revascularization is time-dependent," Neurology, vol. 73, no. 13, pp. 1066-1072, 2009. 


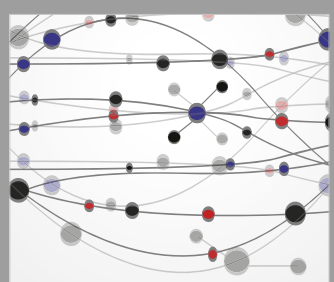

The Scientific World Journal
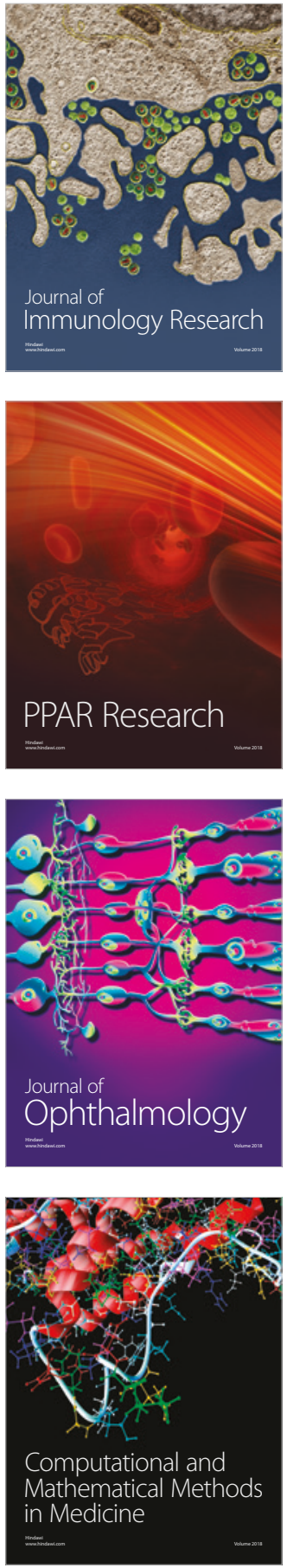

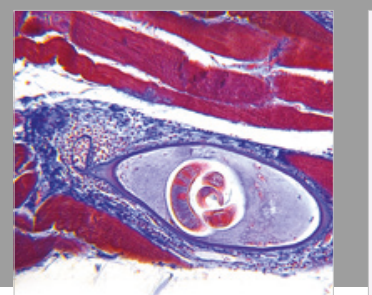

Gastroenterology Research and Practice

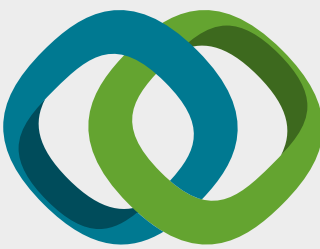

\section{Hindawi}

Submit your manuscripts at

www.hindawi.com
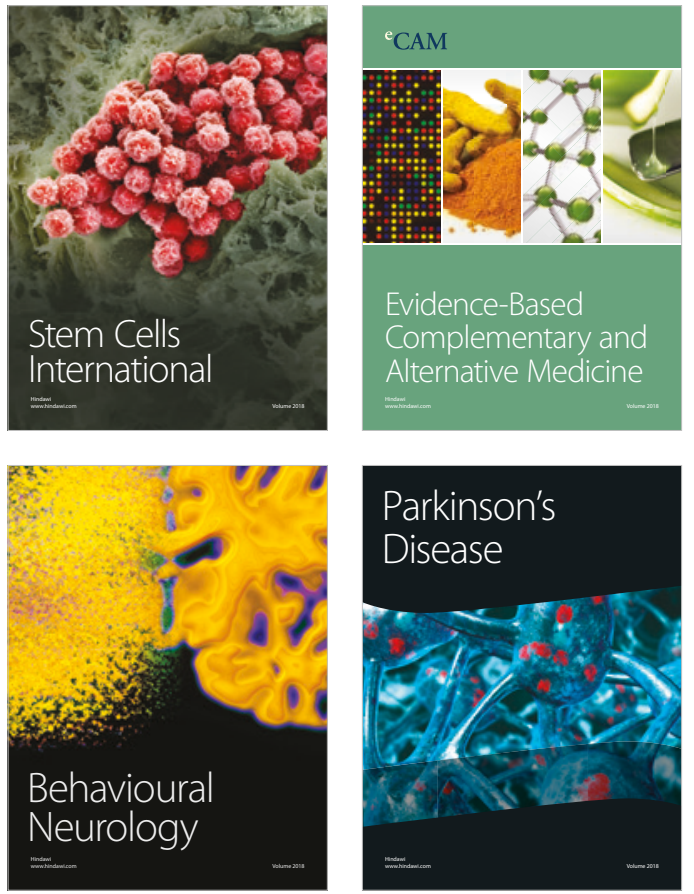

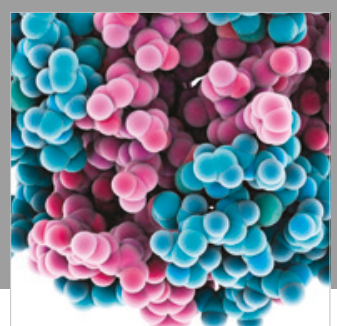

ournal of

Diabetes Research

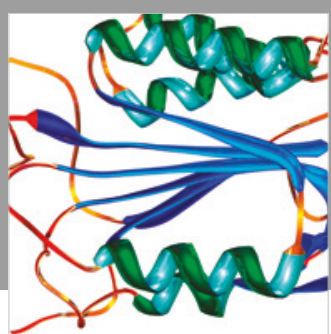

Disease Markers
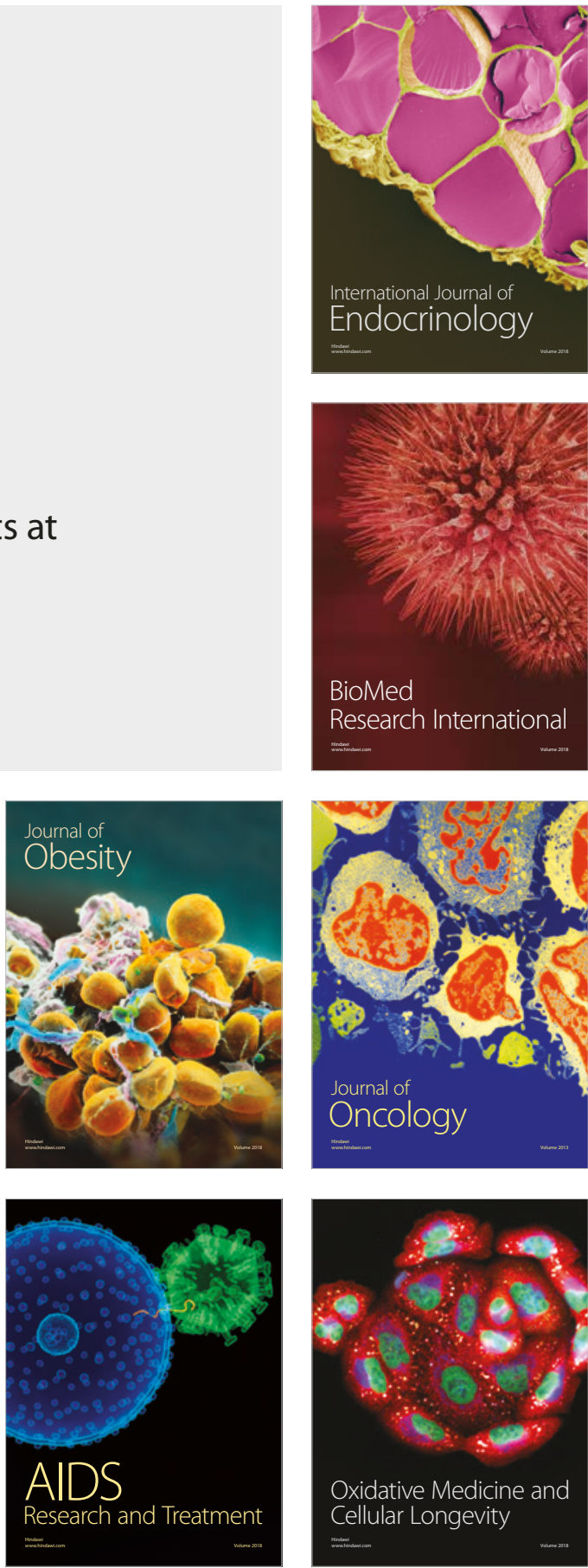